\title{
EL PATRIMONIO ESCOLAR EN LOS MUSEOS DE ASTURIAS
}

\section{The beritage school in the Asturias museums}

\author{
Carmen Diego Pérez y Montserrat González Fernández \\ Universidad de Oviedo \\ Correo-e: cdiego@uniovi.es; montseg@uniovi.es
}

Recepción: 17 de noviembre de 2015

Envío a informantes: 28 de noviembre de 2015

Aceptación definitiva: is de diciembre de 2015

Resumen: En este artículo analizamos el proceso de salvaguarda del patrimonio educativo asturiano iniciado a finales de los años ochenta del siglo xx. Para ello reconstruimos sus primeros pasos, describimos la evolución y situación actual de las colecciones museográficas consolidadas y los posibles efectos que ejercen en el territorio y la cultura de esta región. Las colecciones exhibidas tienen mayoritariamente carácter etnográfico, están instaladas en un hábitat rural y muestran mobiliario y enseres utilizados en la enseñanza primaria durante el siglo xx. El análisis reconoce las aportaciones de los historiadores de la educación como saber de referencia para el patrimonio escolar y plantea la necesidad de que futuras investigaciones aborden en mayor profundidad la «representatividad» de los objetos utilizados en la enseñanza.

Palabras clave: Patrimonio educativo; museo escolar; patrimonio cultural; desarrollo comunitario en Asturias.

AвsтRAct: In this article we analyze the safeguard process of Asturian educational heritage, which began at the eighties of the zoth century. For reaching this purpose, we have rebuilt its first steps, described the evolution and actual situation from the consolidated museographic collections and the possible effects that they have onto the territory and culture of this region. The exhibited collections have mainly ethnographic character, are settled in a rural habitat and show furniture and basic tools used in the primary education during the 2oth century. The analysis recognizes the contributions made by the historians of education as reference knowledge for the school heritage, and suggests the need so that future investigations deal, in a deeper way, with the representation of the objects used in the teaching.

KEY wORDs: Educational heritage; school museum; cultural heritage; community development in Asturias. 
EL PATRIMONIO ESCOLAR EN LOS MUSEOS DE ASTURIAS CARMEN DIEGO PÉREZ Y MONTSERRAT GONZÁLEZ FERNÁNDEZ

\section{El estudio del patrimonio escolar}

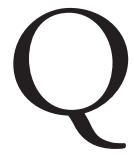

ue la Historia de la Educación estudia lo que ocurre dentro y fuera de las aulas es obvio, sin embargo, su interés por los objetos y útiles propios de la enseñanza empezó a manifestarse en nuestro país hace unos treinta años, comenzando con el estudio de los libros de texto ${ }^{\mathrm{I}}$. Poco a poco, por iniciativa de varios historiadores de la educación y coleccionistas, empezaron a proliferar en varios lugares exposiciones sobre temática escolar (Hernández Díaz, 2003: I2I-I42) que pretendían acercar al público la cultura material del proceso escolarizador, pues éste -como consecuencia de la Ley General de Educación de 1970- empezaba a cambiar tanto en su estructura interna como en los materiales utilizados en la enseñan$\mathrm{za}$, al abandonarse unos (las enciclopedias, por ejemplo) y renovarse otros (bancos y mesas, pupitres bipersonales, plumas, tinteros, cuadernos...). La idea de que estos objetos eran bienes museables arrancó simultáneamente al acercamiento de los historiadores de la educación a la etnografía, la antropología y la microhistoria (Carreño, 2007: 9I-95), convencidos de que «el patrimonio escolar es un bien para ser mostrado públicamente y para ser examinado por todos» (Escolano, 2009: 9), implicándose en la construcción y comunicación de los valores de la memoria no por nostalgia sino por responsabilidad pública. Al aplicar estas perspectivas historiográficas se «sitúa a los museos de educación como los mediadores insoslayables... porque ellos albergan la cultura etnográfica de las instituciones educativas» (Carreño, 2007: 96) y se comienza a construir el soporte epistemológico necesario al tiempo que el interés etnográfico de los historiadores de la educación trascendía a la sociedad, que acudía a exposiciones temporales, germen de exposiciones permanentes y de posteriores museos escolares.

Al desarrollo de museos de temática educativa también contribuyó la aprobación, en 1985, de la Ley del Patrimonio Histórico Español que considera patrimonio «los inmuebles y objetos muebles de interés artístico, histórico, paleontológico, arqueológico, etnográfico, científico o técnico» (artículo 2), pues edificios escolares, muebles, libros y objetos utilizados en la enseñanza, así como la documentación generada por las instituciones educativas, son indudablemente patrimonio. En la actualidad, son ya decenas los museos de carácter educativo ${ }^{2}$ vinculados a diferentes administraciones, instituciones, fundaciones..., siendo algunos de ellos virtuales. De los pasos dados en el Principado de Asturias en relación a la museología escolar tratamos en las siguientes páginas.

\section{El estado del patrimonio escolar en Asturias}

La historia cultural de Asturias es análoga a la de otros territorios vecinos según el estudio del antropólogo Ramón Valdés, pues «la identidad cultural de Asturias se difumina, se disuelve por el Este, por el Oeste y por el Sur en identidades mucho más

Uno de los estudios pioneros en nuestro país fue el de Delgado, B. (1983) Los libros de texto como fuente para Historia de la Educación. Historia de la Educación. Revista Interuniversitaria, 2, 353-358.

El primero fue el Museo Pedagógico de Aragón en Huesca (1987), el Museo del Niño y Centro de Documentación Histórica de la Escuela en Albacete (1989), el Museo Pedagógico. La última escuela de Otones de Benjumea (1996), el Museo Pedagóxico de Galicia en Santiago de Compostela (2000)..., el Museo de la Educación de la Universidad del País Vasco (2014). 
amplias» (1987: 320). Señala que, situada entre la cordillera Cantábrica y el mar, su orografía, sus instituciones, sus modos de subsistencia, determinados elementos de su cultura material (el hórreo o el carro del país) son similares a los de las provincias vecinas, pues son fruto de muchos siglos de intercambios culturales y añade que también la lengua se habla fuera de sus $10.603 \mathrm{~km}^{2}$ (por ejemplo, en Miranda de Douro, en Portugal). Si aplicamos la óptica macroscópica de este antropólogo encontramos que la cultura material de la escuela asturiana tampoco es esencialmente diferente a la de otras comunidades, pero la protección, conservación y exposición del patrimonio educativo tiene matices y modalidades que presentamos en las siguientes páginas. De hecho, no fue hasta la última década del siglo xx cuando en el Principado de Asturias empezaron el interés y el esfuerzo por salvar parte del patrimonio escolar que estaba en riesgo -otro ya se había destruido- debido al cierre de muchas escuelas unitarias rurales para concentrar a maestros y alumnos en colegios de Educación General Básica, proceso que se inició en 1970. Según Rozada y Terrón (2004: 554), las escuelas unitarias eran el tipo más frecuente en nuestra región, hasta el punto de que en veintiún de los setenta y ocho municipios todas sus escuelas eran de esta clase y su cierre conllevó cambios en la vida de los pueblos.

La salvaguarda del patrimonio cultural empezó por la elaboración de inventarios y catálogos promovidos por profesores de la Universidad de Oviedo, por ejemplo, el estudio pionero sobre el patrimonio industrial histórico en 1987 que, para algunos estudiosos (Sabaté y Benito, 20I0: Io), tienen el indudable mérito de haber reclamado la condición de recursos patrimoniales para los restos industriales. En esta línea, creemos, se deben interpretar también los primeros pasos dados por cuatro jóvenes profesoras de la Universidad de Oviedo que abordaron, en 1989, con entusiasmo y sin financiación, la tarea de estudiar el patrimonio de las Escuelas Selgas con su singular edificio, mobiliario y enseres. Esta institución se transformó en 1995 en un Instituto de Enseñanza Secundaria que sólo conservó la fachada original del edificio, un atropello más de nuestro patrimonio educativo ${ }^{3}$, pues ya se había llamado la atención sobre él y, además, en 1993, poco antes de iniciarse las obras, el Vicerrectorado de Relaciones Institucionales de la Universidad de Oviedo había encargado a las citadas profesoras el Inventario-Catalogación del Patrimonio pedagógico y escolar de la Fundación Escuelas Selgas de Cudillero, en el que se recordó el singular valor del interior de este edificio. En esos años estas profesoras también abordaron la sensibilización de la comunidad y la difusión del patrimonio educativo mostrando parte de este en varias exposiciones desde 1990, comenzando por el entorno inmediato: la Facultad de Filosofía y Ciencias de la Educación de la Universidad de Oviedo ${ }^{4}$, continuando en

Véase al respecto el capítulo 4. Unas infraestructuras óptimas: edificio y mobiliario de las Escuelas Selgas. En A. Terrón Bañuelos y A. Mato Díaz (coords.) (1992) Un modelo escolar integrador y reformista: la Fundación Escuelas Selgas. Oviedo: KRK (2. ${ }^{a}$ ed. en 2006). Los avatares de las profesoras implicadas en la salvaguarda de estas escuelas antes de abrir como museo están descritos en A. Terrón Bañuelos (2003) El proceso de creación del Museo Escolar Selgas: un análisis crítico. En V. Peña SAavedra (coord.) I Foro de Museísmo Pedagóxico. O museísmo pedagóxico en España e Portugal: itinerarios, experiencias e perspectivas. Actas (pp. 283-290) S. l.: Xunta de Galicia, Consellería de Educación e Ordenación Universitaria, Secretaria General, Museo Pedagóxico de Galicia.

4 La primera fue El ayer del aula, una mirada hacia el pasado, mostrada del i2 al i6 de noviembre de I990 preparada por Violeta Álvarez, Carmen Diego, Montserrat González y Aida Terrón. Estas profesoras también organizaron las exposiciones a las que nos referimos en la siguiente nota y algunas de ellas en las mencionadas en la nota 6 . 
espacios museísticos arraigados 5 y aprovechando otros eventos relacionados con la educación ${ }^{6}$. El eco de estas exposiciones en la prensa, la radio y la televisión regionales probablemente ayudó a generar un estado de opinión favorable a la conservación del patrimonio escolar, a atraer la atención del público en general, de los docentes y de algunas corporaciones pues, a partir de la década siguiente, constatamos la incorporación de material escolar en algunos museos etnográficos, en museos particulares, en aulas-museos ubicadas en centros escolares en activo o en museos monográficos, que presentamos a continuación.

Sin embargo, la administración asturiana ha mostrado un tardío interés por el patrimonio educativo, pues hasta 2014 no incorporó una selección de 120 escuelas al inventario del patrimonio cultural de Asturias ${ }^{7}$ y, a nuestro juicio, esa actuación necesaria ha quedado incompleta porque no fue acompañada de idéntica atención para el ajuar escolar y la documentación oficial generada (como libros de matrícula o de visitas de inspección, etc.). Esta falta de atención favorece la desaparición de fuentes primarias e incrementa el problema de la falta de documentación escolar-muy escasa en nuestra Comunidad Autónoma por haber sufrido los archivos varias destrucciones-, lo que unido al hecho de que cuando se cerraron las escuelas no se envió la documentación generada al lugar oportuno, contribuye a su desaparición por abandono, sustracción o destrucción interesada. Una tarea pendiente es, pues, intentar recuperar los posibles restos del utillaje, del mobiliario y de la documentación escolar.

No obstante, en Asturias se conserva y expone patrimonio educativo, bien vinculado a otras colecciones o actividades, bien utilizando antiguas escuelas para mostrarlo monográficamente. Así, actualmente son diez los municipios que albergan otras tantas colecciones con mobiliario y enseres escolares utilizados en la enseñanza primaria durante el siglo xx. Cinco de estas colecciones están instaladas dentro de otro museo: en la Fundación Selgas Fagalde, en Cudillero -un museo privado conformado por el palacio y los jardines de esta familia- y en cuatro etnográficos, que muestran las actividades tradicionales de la zona, en los municipios de Quirós, Grandas de Salime, Somiedo y Gijón. Otras dos colecciones vinculan el pasado y el presente de la escolarización al ser instalados los materiales en aulas de colegios en funcionamiento, caso del aula museo de San Antolín de Ibias y la de Caborana, que prevé abrir sus puertas antes de finales del 2015. Finalmente, en tres casos se reconvirtieron antiguas escuelas en museos escolares: Viñón (Cabranes), Puentevega (Pravia) y San Luis (Boal), que alberga también el Centro de Interpretación de la Emigración.

La exposición Antón y la Escuela, mostrada desde el is de mayo al is de septiembre de 1992 en el Centro de Escultura de Candás, Museo Antón, El ambiente del aula de los años 20, Escuelas Selgas, desde el 25 de septiembre al I8 de octubre de 1992 en el Museo Evaristo Valle de Gijón.

6 Ejemplos fueron Patrimonio pedagógico de las Escuelas Selgas, exhibida en el Edificio Histórico de la Universidad de Oviedo, con motivo de la inauguración del curso, desde el 30 de septiembre al 26 de octubre de 1994; La escuela del siglo XX, mostrada en el C. P. Torner de Gijón durante el mes de junio del 2000; La enseñanza en tiempos de la república y la dictadura y Alcordanza de la escuela pública, exhibidas en la Casa de la Cultura Escuelas Dorado de Sama dentro de los III y IV Encuentros por la Escuela Pública celebrados en Langreo, durante los meses de marzo de 2002 y abril y mayo de 2003, respectivamente.

Véase la Resolución de 6 de febrero de 20I4, de la Consejería de Educación, Cultura y Deporte, por la que se incoa expediente para la inclusión en el Inventario del Patrimonio Cultural de Asturias de una selección de rzo escuelas de interés patrimonial existentes en Asturias, Boletín Oficial del Principado de Asturias de 48 de 27 de febrero de 20I4, I-247. 
Todas estas colecciones están ubicadas en zonas rurales, pues el Museo del Pueblo de Asturias -de carácter etnográfico-, a pesar de estar instalado en Gijón, comenzó a crearse trasladando varias construcciones típicas de los pueblos (hórreos, paneras, casa campesina terrena...) y su misión es conservar y difundir la memoria del pueblo asturiano, preservando testimonios variados de la vida cotidiana, tanto del medio rural como urbano. Los objetos relacionados con lo escolar (libros, diplomas, juguetes...) están dispersos en varios de sus fondos y colecciones (fototeca, archivo de la tradición oral...) y con ellos plantea exposiciones temporales itinerantes por la Red de Museos Etnográficos de Asturias. Otro rasgo común es que estos ayuntamientos tienen mayoritariamente una economía agraria y han perdido población sistemáticamente en las tres últimas décadas -salvo Gijón-, lo que afecta al mercado laboral y a la organización de los servicios públicos.

\section{I. Colecciones escolares vinculadas a otros espacios}

En este apartado caracterizamos las colecciones escolares que se muestran en espacios compartidos: museos etnográficos, formando parte de un museo privado y en colegios en funcionamiento.

\section{I.I. Aulas en museos etnográficos}

La incorporación de lo escolar en los museos etnográficos se produjo años después de su apertura, lo que indica que éste es un bien etnográfico que ha tardado en ser reconocido como patrimonio cultural y quizá el incorporar esta nueva colección en sus guías y catálogos ayude a difundir éste ${ }^{8}$. La presencia de lo escolar en los museos etnográficos de Grandas de Salime y Quirós queda reducida al intento de recrear un aula utilizando diversos elementos habituales en una escuela: pupitres, mesa del maestro, crucifijo, cuadros religiosos y de políticos, mapas, pizarra, libros, cuadernos, globo terráqueo, tinta, etc. El valor determinante para seleccionar lo mostrado parece ser la antigüedad de los objetos y eso hace que estas colecciones reúnan elementos de diversas épocas mostrando lo conservado de manera asíncrona, hecho comprensible si pensamos en la permanencia, por ejemplo, del mobiliario o en la continua renovación de diversos útiles escolares (lápices, tinta, pluma, papel, cuadernos, mapas...). En general, se utiliza una bandera, un escudo o un retrato para evocar en el visitante un tiempo concreto y así acaban transmitiendo un mensaje confuso, pues se contextualiza parcialmente lo representado.

8 En las dos primeras guías del visitante publicadas por Museo Etnográfico de Grandas de Salime, en 1984 y 199I, no hay referencias a estos objetos y sí aparece en la tercera: NAvEIRAS EsCANLAR, J.; LópeZ Álvarez, J. y Graña García, A. (200I) Guía del Museo Etnográfico de Grandas de Salime. Grandas de Salime, s. n., que nos dice que los materiales proceden de la escuela Pezós (p. 29) y están instalados en un pequeño local de la Casa Rectoral, en la misma sala en la que se muestra la industria textil. En el caso de Quirós, que abrió en 1998, se dedican un par de páginas (pp. 91-92) a describir la historia escolar del concejo pues tiene una pequeña sala con material escolar, pero no se documenta la colección, véase RED DE MusEOS Etnográficos de Asturias (2004) Museo Etnográfico de Quirós. Guía del visitante. Bárzana de Quirós: Imprenta Mercantil Asturias. 
Dentro de los museos etnográficos, el eco-museo de Somiedo especializado en «Los oficios y la trashumancia» merece unas líneas, pues su tercera sede 9 está en el edificio de las antiguas escuelas de Caunedo, cofinanciadas por el Estado y por José Fernando Feito Taladrid ${ }^{10}$, vecino emigrado a Cuba, quien además amuebló todos los espacios: el aula de niños y la de niñas, despachos de los maestros y biblioteca. El edificio, con acceso y patios diferentes, fue inaugurado en 1953 como escuela unitaria de niños y niñas con un aula en cada piso y la vivienda de los maestros exenta. En aquella fecha también se instaló en la planta baja un taller de carpintería con la finalidad de enseñar a los jóvenes de la zona un oficio acorde con el territorio. Al construirse una escuela-hogar en Pola de Somiedo se cerraron todas las escuelas rurales, pues a ella acuden todos los escolares del municipio desde el curso 1982-1983. Esta de Caunedo funcionó como escuela tallerr entre 1998 y 2004 y abrió como espacio museístico el 29 de octubre de 2orI, tras la rehabilitación del edificio ${ }^{\text {r2}}$.

Actualmente en el sótano del museo se muestran instrumentos de oficios relacionados con la madera que ofertó esta escuela en su origen (de carpintero y de madreñero) y como escuela taller. Además, en otro edificio exento se exponen útiles de otros oficios propios de la zona: cantero, cestero y herrero. En la primera planta del edificio se conserva el aula de niños y el mobiliario con el que fue dotada en los años cincuen$\mathrm{ta}^{13}$, el despacho del profesor y la biblioteca con cuatro armarios-mesa con cuatro puestos cada uno. Éste es el único caso en el que no hubo acopio de objetos escolares ajenos a esta institución y también el único con edificio y enseres de la segunda mitad del siglo xx. El segundo piso está dedicado a la trashumancia y a uno de los tipos de ésta: los «vaqueiros de alzada», un grupo cultural propio de esta zona de Asturias.

\section{I.2. Una colección escolar en un museo privado: la Fundación Selgas Fagalde}

En Cudillero, municipio costero y turístico, se puede visitar desde el año 2002 una exposición escolar en la Fundación Selgas Fagalde, ubicada en El Pito. En su página web afirman que «la creación de este museo escolar es fruto de una ardua y prolongada tarea que se inició en los primeros años de la década de los 9o, una vez que el edificio que albergaba las Escuelas fue habilitado como centro de enseñanza secundaria» ${ }^{14}$. Ya hemos

9 La sede principal, «Los oficios y la trashumancia», se encuentra en Caunedo, a escasos dos kilómetros de Pola de Somiedo, donde se encuentra otra sede al aire libre y tres casas con techos de paja («teitos») en Veigas.

to El Estado subvencionó el edificio escolar con 80.000 pesetas, siendo el coste total de la construcción de la escuela 348.353,64 pesetas y el de la vivienda de los maestros ascendió a I88.634 pesetas.

II Las escuelas taller se crearon en 1985 para formar a personas desempleadas menores de 25 años. Con ellas se recupera el patrimonio artístico, histórico, cultural o natural, se rehabilitan entornos urbanos o del medio ambiente.

${ }_{12}$ Éste fue uno de los proyectos financiados por el Plan Español para el Estímulo de la Economía y el Empleo (Plan E.), puesto en marcha por el Gobierno en noviembre de 2008 y con fondos del Grupo de Desarrollo Rural (GDR) del Camín Real de la Mesa.

${ }_{13}$ En el aula hay un reloj de péndulo, dos pizarras de doble altura, mesa del profesor, pupitres unipersonales poco habituales pues son silla-mesa de metal y madera que reposan sobre dos listones de madera. El tablero que hace de mesa está unido a la silla y tiene un hueco para el tintero. Debajo del asiento está ubicado el cajón. En el aula hay una chimenea y en dos de sus paredes se muestran exposiciones fotográficas itinerantes de la Red de Museos Etnográficos de Asturias.

${ }^{14}$ Véase en la página web de la Fundación Selgas Fagalde, http://www.selgas-fagalde.com/, la sección «Museo escolar». 
aludido a que el proceso de estudio y salvaguarda del edificio y los enseres se inició antes de cerrar las Escuelas Selgas ${ }^{\text {Is }}$ y a que ello fuera posible contribuyó el cuidado y aprecio de los maestros que lo habían conservado en buen estado y habían empezado a inventariar la colección de libros de texto. Otros expertos historiadores de la educación -y especialmente el primer presidente de la Sociedad Española para el Estudio de Patrimonio Histórico Educativo, Julio Ruiz Berrio, que lo visitó- también percibían el edificio original y los enseres de estas escuelas como un buen ejemplo de «escuela-museo» para que el patrimonio estuviera in situ -como el de Gante y el de Oslo-, pero finalmente se perdió la ocasión de convertir en museo uno de los edificios escolares modélico por su arquitectura (Ruiz, 2002: 56) y por sus espacios escolares -su interior, sus patios, y el edificio del comedor y teatro- pues fueron derribados.

Las iniciales llamadas de atención sobre el valor del continente y del contenido sólo consiguieron que finalmente la Fundación cultural privada Selgas Fagalde, reconocida en I992, no se deshiciera del mobiliario y del material didáctico con que habían sido dotadas en 1915 y con una parte de ellos conformaron la colección que se muestra ahora en una sala ad hoc en uno de los edificios del Palacio. El hecho de haberse conservado la dotación original, adquirida por la familia Selgas en varios países de Europa, caracteriza lo expuesto, pues los enseres escolares son más y más variados que los habituales en cualquier escuela o exposición escolar asturiana, pues conserva varios elementos singulares como una carta sincronológica de historia universal de 70 por 750 centímetros, pupitres bipersonales específicos para niñas, gabinetes de física, de química y de historia natural con animales disecados y reproducciones de arados, vitrinas con colecciones de medidas del sistema métrico decimal, etc.

\section{I.3. El aula-museo en centros escolares en funcionamiento}

A diferencia de las aulas en museos etnográficos, que hacen una representación artificial con objetos reales, las dos aulas-museo ubicadas en colegios en activo son espacios reservados y dedicados a mostrar objetos escolares en desuso en su entorno natural. Veamos qué singularidades presentan cada uno de ellas.

El Aula Museo del Centro Público de Educación Básica Aurelio Menéndez de San Antolín (Ibias), nacida de una exposición en 1999, fue inaugurada en diciembre de 2004. Esta aula-museo tiene acceso exterior independiente del edificio escolar y alberga documentos (escritos, libros de escolaridad, archivos, expedientes...), mobiliario y enseres típicos de mediados del siglo xx procedentes mayoritariamente de la escuela de Villarcebollín, así como fotografías de una veintena de escuelas rurales de ese concejo. Esta aula-museo incrementó su colección con donativos ${ }^{16}$, que permiten conocer mejor la historia de la escolarización en este municipio. Las visitas son posibles gracias a la directora del centro, pues las administraciones no proporcionan el soporte necesario para abrir al público de manera regular.

A finales de este año 2015 abrirá sus puertas una nueva aula-museo instalada en el Colegio Rural Agrupado Maestro don José Antonio Robles en Caborana (Aller),

is Otra prueba de ello es el siguiente artículo: Escuelas Selgas, un patrimonio a conservar. El Comercio, 8 de mayo de I99I, 40 y las obras citadas en la nota 3.

${ }_{16}$ Por ejemplo, seis cartas de maestros e inspectores dirigidas a Adolfo Díaz Peñamaría, alcalde de Ibias entre I931 y 1936, que fueron depositadas por su hija. Véase en la revista escolar Connio de junio, 20I5 el artículo de José A. Ron Tejedo comentando estas cartas que enviaron al alcalde los maestros entre 1932-I934. 
anteriormente denominado Río Negro. El edificio, construido por la Sociedad Hullera Española, se inauguró en 1922, encargándose las Dominicas de la Anunciata de la enseñanza de las niñas y en 2005 se convirtió en una de las sedes del CRA ${ }^{17}$. Fue la actuación del entonces director del CRA la que puso a salvo los útiles de la enseñanza que ahora se expondrán permanentemente al público. Esta colección la conforman piezas habituales como pupitres de diversos tipos, globos terráqueos..., pero también material audiovisual y musical..., procedente en su mayoría del periodo en que funcionó como colegio privado.

\subsection{Antiguas escuelas convertidas en museos escolares}

En Asturias varias escuelas en desuso, tras un periodo de abandono, han sido reconvertidas para prestar otros servicios a la población: centros culturales como el ubicado en las escuelas de Balmori (Llanes) ${ }^{18}$; aulas didácticas como la dedicada al conde de Campomanes en su pueblo, Sorriba (Tineo); museo de apicultura en Tanes (Caso); centros sociales; residencias geriátricas..., y cuatro antiguas escuelas fueron reconvertidas en museos escolares, siendo la más reciente la de Caunedo, sede del eco-museo de Somiedo, a la que ya nos hemos referido. Las otras tres, Boal, Cabranes y Pravia, ofertan las únicas colecciones contextualizadas en viejas escuelas en las que se reunieron mobiliario y objetos tanto de ellas como de otras del entorno.

Estos tres museos comparten también el pertenecer a municipios afectados por la emigración a América desde finales del siglo XIX. Los oriundos de estos concejos se asociaron allá y mantuvieron lazos con su lugar de origen y se preocuparon por mejorar las infraestructuras (casas, escuelas, fuentes, caminos...). En Iberoamérica surgieron varias sociedades de instrucción como la Sociedad de Instrucción Naturales del Concejo de Boal, creada en i9ıi, que financió la construcción de 2i escuelas (convirtiéndose así en la Sociedad que mayor cantidad de escuelas construyó). También los emigrantes de Cabranes fundaron una sociedad en La Habana: el Club Cabranés y en el municipio de Pravia se conservan numerosas «casas indianas» entre Peñaullán y Somao.

Los tres municipios se caracterizan también por tener poca densidad de población (I4,2I; 28,06 y 85,46 habitantes por $\mathrm{km}^{2}$ respectivamente) y estar ésta envejecida, su hábitat es mayoritariamente rural y en los últimos años han incrementado las plazas en establecimientos hoteleros y alojamientos de turismo rural, con la confianza en que la apertura de museos contribuiría a atraer más visitantes, por lo que es perceptible una modificación de sus actividades económicas. En el caso de Boal se quería llamar la atención sobre «la importancia cultural del legado patrimonial en el Parque Histórico del Navia» ${ }^{19}$ con la intención de articular y mejorar la economía de los nueve municipios de la comarca Navia-Porcía al atraer el turismo con el reclamo medioambiental

${ }^{17}$ En 2005 se convirtió en Colegio Rural Agrupado Caborana-Río Negro y en agosto de 2009 se sustituyó este nombre por el de Maestro don José Antonio Robles, antiguo director.

i8 Instalado en el antiguo colegio María Dolorosa y San José que abrió sus puertas en i9o4, conserva un espacio con pupitres y otros objetos escolares de cuando cerraron el colegio en I972, que fueron restaurados por los vecinos.

${ }_{19}$ Véase en p. 32 La Nueva España del viernes i3 de febrero de 2004, el artículo Jornadas sobre la emigración y la instrucción pública en Boal. 
y cultural, creando el citado Parque Histórico del Navia, al que también pertenece el Museo Etnográfico de Grandas de Salime.

Estas tres colecciones, instaladas en su contexto natural, difieren en tamaño. La de mayor entidad es la del Museo de la Escuela Rural de Asturias en Viñón (Cabranes), pues ocupa el edificio que albergaba la escuela de niños y de niñas y la casa del maestro; las otras son escuelas próximas a la capital del municipio: la de niños de Puentevega, que alberga el Aula Museo Alberto Martínez (Pravia) y las escuelas de San Luis (Boal), dedicadas a mostrar las aportaciones de los emigrantes a la instrucción pública.

\subsection{El Aula Museo Alberto Martínez en Puentevega (Pravia)}

En las antiguas escuelas de Puentevega, que mantuvieron su actividad desde diciembre de I9I8 hasta el curso I974-1975, están instalados en la escuela de niños el Aula Museo Alberto Martínez y en la de niñas el Centro Social del Valle de Arango. La idea de su reutilización partió de la corporación local, que tenía interés en conservar el edificio y fue impulsada por la asociación de vecinos, que restauró mobiliario y enseres (pupitres, sillas, encerados, armarios, estufa...) ${ }^{20}$ y donó cuadernos y otros objetos. La colección, que comenzó a mostrarse en 2004, refleja una escuela rural durante el siglo xx y en las paredes exhiben fotografías de alumnos y maestros -precisamente, lleva el nombre de un antiguo alumno- $-^{21}$. A los vecinos de cierta edad les enorgullece, en palabras de la entonces alcaldesa, el buen estado de conservación: «Está todo como estaba en sus orígenes, hasta el suelo es el auténtico» ${ }^{22}$.

2.2.2. El Centro de Interpretación de la Emigración y la Instrucción Pública en San Luis (Boal)

La colección instalada actualmente en las antiguas escuelas de San Luis tuvo su origen en una exposición permanente ubicada en las antiguas escuelas graduadas de Boal -hoy Centro Público de Educación Básica Carlos Bousoño- con la que se habían celebrado unas Jornadas sobre La emigración e instrucción pública en febrero de 2004. Entonces se reunieron objetos (pupitres, armarios, láminas, mapas, pizarras, cuadernos escolares, dibujo, ábacos...) procedentes de todas las escuelas de este municipio, construidas mayoritariamente por los oriundos que emigraron a América, así como una maqueta del proyecto original de una escuela para Boal hecha en I9I4 por Francisco Bousoño, entonces presidente de la Sociedad de Instrucción de los Naturales de Boal en La Habana. La intención de los regidores municipales de llevar el turismo a su territorio hizo que en julio de 2007 se volviera a inaugurar en el

${ }_{20}$ Véase el documental Pueblos. Puentevega en http://www.rtpa.es/video:Pueblos_55I405378858.html y la información sobre este espacio expositivo en http://www.bajonalon.es/web/fichacentrovisitable/id/5/ titulo/aula-museo-alberto-martinez.

21 Alberto Martínez González fue comandante de caballería del Ejército de Tierra y el máximo responsable de los servicios secretos españoles. Murió en una emboscada junto a seis compañeros del Centro Nacional de Inteligencia (CNI) en Latifiya (Irak) el 29 de noviembre de 2003.

${ }_{22}$ El Comercio digital, domingo, 3 de diciembre de 2006. Recuperado el 3 de junio de 20Io, de http:// www.elcomercio.es/prensa/20061203/aviles/escuela-ayer_20061203.html. 
nuevo emplazamiento ${ }^{23}$ y que se enriqueciera la colección con objetos cedidos por los vecinos ${ }^{24}$. Tiene objetos similares a otras colecciones y algunos otros singulares como una colección de insectos, diplomas de premios concedidos por la Sociedad de Instrucción de los Naturales de Boal, fotografías de las diferentes escuelas del concejo y grupos de maestros con escolares, objetos y documentos relacionados con la emigración americana.

\subsubsection{El Museo de la Escuela Rural de Asturias en Viñón}

Hemos dejado para el final el único museo que lleva este nombre y tiene mayor entidad. El museo está instalado en el primer edificio escolar que tuvo el municipio de Cabranes, construido en un solar donado por el marqués del Real Transporte, con el apoyo económico de los emigrantes, el trabajo de los vecinos y los materiales donados por la Sociedad Minas de Viñón. Esta casa-escuela se inauguró en 1908 y funcionó como tal hasta 1970. En diciembre del 200 i el Ayuntamiento puso en marcha en este edificio recién restaurado Los Museos de Cabranes. Inicialmente el objetivo era aprovechar las subvenciones anuales a corporaciones locales para abrir un museo de carácter etnográfico especializado en cerámica tradicional asturiana con la colección de uno de los vecinos; pero los problemas del Ayuntamiento para justificar en el plazo previsto las subvenciones recibidas, junto con la negativa del propietario a aceptar las condiciones de cesión de su colección, obligó a que se abriera con piezas cedidas o prestadas por particulares. Esta carencia inicial de colección museográfica hizo que comenzase una búsqueda de posibles objetos para aumentar la colección y, en ese proceso, la museóloga contratada se encontró con «una extensa colección de piezas y materiales pertenecientes a antiguas escuelas rurales desafectadas por el Ayuntamiento ${ }^{25}$ que había sido reunida por los maestros del Colegio Rural Agrupado La Coroña. Meses más tarde de su apertura -en julio de 2002- se instaló en la segunda planta una exposición escolar, que será el origen de la colección finalmente exhibida, relativa a la escuela rural en la región.

La intención inicial de la corporación cabranesa era potenciar la economía, pues sus habitantes se dedicaban básicamente a la actividad agroganadera. En la última década del siglo en Cabranes empieza a destacar el sector servicios, al abrirse varios hospedajes rurales ${ }^{26}$ y otras actividades turísticas. Posiblemente la apertura de este museo haya contribuido a atraer más visitantes, pero sería necesario que durante estos años hubiese registrado datos, por ejemplo, del número de visitantes. No obstante, lo

23 Véase en La Nueva España, del domingo is de julio de 2007, Boal realza su pasado indiano. El concejo inaugura el Museo de la Emigración y la Instrucción Pública, un equipamiento del parque histórico que homenajea a los emigrados a América, p. 24.

${ }_{24}$ Tras permanecer abierto hasta finales de septiembre de ese año, las visitas tienen que concertarse previamente, sin embargo, hay la posibilidad de una visita virtual. Véase http://www.deturismoporasturias.com/asturias/museos/centro-de-interpretacion-de-la-emigracion-y-la-instruccion-publica-de-boal-or25310/index.html\#visitas_virtuales.

${ }_{25}$ García Egure, Marta (20Io) Relación museo-territorio e implementación didáctica: Museo de la Escuela Rural de Asturias (pp. 205-206) Tesis doctoral. Universidad de Oviedo.

${ }_{26}$ En 2006 había 4 establecimientos hoteleros y 14 alojamientos de turismo rural y en 2013 había 4 y 24 respectivamente. Véase Sociedad Asturiana de Estudios Económicos en http://www.sadei.es/es/portal. dolos datos relativos a este municipio. 
que está bien documentado es la participación de los habitantes en el largo proceso de apertura como Museo de la Escuela Rural ${ }^{27}$. Los naturales de este municipio cedieron y donaron objetos, participaron en la restauración de los mismos, como exalumnos guiaron a los visitantes, participaron en documentales narrando sus vivencias que hoy en día forman parte de la museografía ${ }^{28}$.

$\mathrm{Su}$ visita tiene interés porque, por una parte, alberga la recreación de las aulas y también de la vivienda de los maestros, amueblada con piezas procedentes de las casas de otros vecinos del municipio y, por otra parte, el edificio está ubicado a 50 metros de la iglesia prerrománica de San Julián, cuyo atrio sirvió de escuela -según documentación conservada en el archivo municipal desde el siglo XviıI- hasta comienzos del siglo xx, circunstancia no contemplada en el discurso expositivo de este museo.

\section{Conclusiones y propuestas}

En general, los museos de esta región no tienen más fondos que lo exhibido, incrementan sus colecciones generalmente por donaciones, apenas realizan actividades de difusión y, dadas sus características, difícilmente pueden cumplir con la investigación, una de las funciones que les asigna la Ley del Patrimonio Histórico Español: «Son museos las instituciones de carácter permanente que adquieren, conservan, investigan, comunican y exhiben para fines de estudio, educación y contemplación conjuntos y colecciones de valor histórico, artístico, científico y técnico o de cualquier otra naturaleza cultural» (artículo 59.3).

El hecho de que algunas colecciones estén instaladas en aulas-museo de centros educativos en funcionamiento o en antiguas escuelas reconvertidas en museos incrementa su interés pues no sólo contextualiza los objetos, sino que muestra un elemento más del patrimonio educativo: la arquitectura escolar, tanto edificios de escuelas como de casas-escuela. La reutilización de las escuelas de San Luis y Caunedo ayudará a conservar estos dos edificios, pues no están incluidas en el Inventario del Patrimonio Cultural de Asturias.

27 Por ejemplo, el edificio fue restaurado por una escuela-taller; se celebraron varios encuentros entre los alumnos del Colegio Rural Agrupado y las personas de mayor edad del municipio dentro del programa «Rompiendo distancias»; varios vecinos exalumnos participaron durante algún tiempo como guías y en un audiovisual para promocionar este museo.

${ }_{28}$ Algunos de ellos están disponibles en red. Véase la página web del Museo de la Escuela Rural de Asturias: http://www.museodelaescuelarural.com. Sobre este museo hay varias publicaciones -además de la citada en la nota 24- a las que nos referimos por orden cronológico: CALAF, R. y GARCíA EGUREN, M. (20Io) El (sic) Museos en Asturias: ejemplo de cómo la comunidad está implicada en la recuperación del legado patrimonial y cómo los museos son motor del desarrollo local. En A. SEmedo y E. N. NAscimento Actas do I Seminário de Investigação em Museologia dos Países de Lingua Portuguesa e Espanhola, vol. I (pp. 330-340). Porto: Universidade do Porto. Faculdade de Letras. Biblioteca digital. Recuperado de Ier. letras.up.pt/uoloads/ficheiros/8137.pdf; Vega Riego, A. y Mato DíAz, Á. (20Io) El museo de la escuela rural de Asturias: un ejemplo de conservación del patrimonio. CEE Participación educativa, I4, I90-I99. Álvarez Álvarez, C. y García Eguren, M. (20II) Museos pedagógicos ¿Museos didácticos? Didáctica de las Ciencias Experimentales y Sociales, 25, I03-ir6; Álvarez Álvarez, C. y García Eguren, M. (2013) Un museo pedagógico en internet: diseño, desarrollo y evaluación. Teoría de la Educación. Educación y Cultura en la Sociedad de la Información, (I4) 2, 197-277; Fabián Llavona, D. (2013) El Museo de la Escuela Rural de Asturias. Cabás, 9, I34-I44. 
Ciertamente, estas iniciativas surgen de manera diferente, pero en casi todas ellas están presentes la comunidad local y los docentes, bien impulsando su gestación o bien aportando objetos. En todos los casos se reunió mobiliario y material didáctico que sirvió de trama de los elementos más singulares de cada exposición (la emigración a América, la colección particular, la historia escolar del concejo o la de la propia escuela) con lo que a los ojos del espectador queda diluido un mensaje más real y preciso: que la red escolar pública durante la primera mitad del siglo xx tuvo una escasa dotación de elementos materiales -una mesa, quizá un armario, unos pupitres, algunas láminas para la enseñanza de la historia o de la geografía, unos pocos libros de lectura, una pizarra...-.

Excepto en el caso de la escuela de Caunedo, el resto de las colecciones muestran objetos de la primera mitad del siglo xx, por lo que sería conveniente, de manera cautelar, tomar medidas de protección para los recursos educativos más actuales (por ejemplo, rescatar los libros de texto utilizados desde 1970, los instrumentos audiovisuales repartidos por las escuelas, así como la documentación administrativa de todas y cada una de las escuelas cerradas). En este sentido sería conveniente que la historia de la educación aportara líneas de actuación señalando la representatividad de los objetos, la importancia de su conservación, el protagonismo de esos útiles en la cultura... para que administradores y agentes sociales dispongan de esa herramienta, sepan a qué atenerse en la valorización de la herencia escolar y cultural y hagan planteamientos coordinados de carácter multidisciplinar (económico, histórico educativo, museológico...).

En el caso de las colecciones escolares vinculadas a otros espacios, el visitante se asoma a un escaparate que intenta representar una «tradición»: la escolarización, con objetos que tienen una historia, que fueron diseñados en un tiempo concreto, que se fueron transformando, que fueron testigos de la vida de varias generaciones de escolares y de maestros, que presenciaron acontecimientos sociales, políticos, históricos diferentes; pero a nada de todo esto alude lo expuesto. Queda así patente la sobredimensión de los valores de uso, simbólico, histórico y emotivo de los objetos y una falta de perspectiva diacrónica que hurta a quien contempla la muestra la información necesaria. También, a nuestro juicio, sería necesario tomar en consideración a los actores del proceso de enseñanza y de aprendizaje para evitar la cosificación y congelación del conocimiento histórico educativo; mejorar la comunicación del mensaje expositivo e incorporar el conocimiento actual sobre la escuela.

El hecho de que el patrimonio escolar esté instalado dentro de la Red de Museos Etnográficos de Asturias -en cuatro de los casos- permite visitarlo en el horario habitual de estas instituciones, atrae a público variado y lo hace más visible; sin embargo, el acceso a la Fundación Selgas -museo privado-, al Museo de la Escuela Rural de Asturias en Viñón, al Aula Museo de Alfredo Martínez de Puentevega y al Centro de Interpretación de la Emigración y la Instrucción Pública de Boal requiere concertar la visita, pues sólo tienen horario regular durante el verano y ésta es una debilidad que tiene que ver con otras dificultades como son la falta de personal y el insuficiente apoyo económico institucional que repercute negativamente en el aprecio del patrimonio escolar, lo que también nos hace echar de menos, en todos ellos, no sólo políticas de difusión, sino también la realización de actividades educativas dirigidas tanto a público adulto como infantil, culto como lego.

Es posible que la presencia de estas diez colecciones ayude a reactivar el territorio en el que se asientan, pues fueron planteadas como un atractivo turístico más, tanto en 
aquellos casos que forman parte de otro museo más amplio como cuando están en edificios ad hoc. Los museos y aulas por sí solos no parecen ser un factor de transformación del entorno a pesar de ser una expresión de la identidad del lugar. Sin embargo, desde el punto de vista histórico-cultural creemos que mejorarían el mensaje que quieren transmitir si se superara la posición conservacionista. Echamos de menos la conexión de la historia cultural con el planeamiento y la voluntad de proyectar el futuro.

La consideración que ha adquirido el legado escolar en Asturias en la última década no debe hacernos olvidar que la conservación, la difusión y el aprecio por el patrimonio escolar deben continuar incentivándose y los historiadores de la educación deben aportar la imprescindible investigación para poder ser, como requiere la Ley del Patrimonio Histórico Español, auténticos museos con una clara función educadora y no meros espacios para contemplar el pasado en su materialidad.

\section{Bibliografía}

Calaf Masachs, R. y Suárez Suárez, M. A. (2OII) Una mirada panorámica sobre los museos de Asturias: entre el espacio real y el espacio virtual. HerE Mus: heritage E museography, (3) 2, 8-I8. (Ejemplar dedicado a Museos en Asturias: patrimonio cultural y patrimonio social).

Carreño, M. (2007) Museología y museografía de la educación. En A. Escolano Benito (ed.) La escuela material de la escuela. En el centenario de la Junta para la Ampliación de Estudios, 1907-2007 (pp. 91-IIo). Salamanca: Gráficas Varona.

Escolano, A. (2009) El patrimonio material de la escuela y la Historia de la Educación. Cuadernos de Historia de la Educación, 6, 7-9.

González Ruiz, J. (2008). Una institución dedicada al Patrimonio Histórico Escolar de Cantabria: el Centro de Recursos, Interpretación y Estudios de la Escuela. CEE. Participación Educativa, 8, 173-182.

Hernández Díaz, J. M. (2003) Museos pedagógicos y exposiciones educativas en España en los inicios del siglo xxi. En V. Peña SaAvedra (coord.). I Foro de Museísmo Pedagóxico. O museísmo pedagóxico en España e Portugal: itinerarios, experiencias e perspectivas. Actas (pp. II7-I7I). S. 1.: Xunta de Galicia, Consellería de Educación e Ordenación Universitaria, Secretaria General, Museo Pedagóxico de Galicia.

López Álvarez, J.; Elola Molleda, M. y García Eguren, M. (20Ii) La complicidad del museo y el territorio: la Red de Museos Etnográficos de Asturias. HerE Mus: heritage $\mathcal{E}$ museography, (3) 2, 3I-37.

Rozada Martínez, J. M. y Terrón Bañuelos, A. (2004) La escuela rural. En J. Rodríguez Muñoz (dir.) Los asturianos. Raíces culturales y sociales de una identidad (pp. 545-560). Oviedo: Prensa Asturiana.

Ruiz Berrio, J. (2002) Pasado, presente y porvenir de los museos de educación. En A. Escolano Benito y J. M. Hernández Díaz (coords.) La memoria y el deseo: cultura de la escuela y educación deseada (pp. 43-65). Valencia: Tirant lo Blanch.

Sabaté Bel, J. y Benito del Pozo, P. (20io) Paisajes Culturales y proyecto territorial: un balance de treinta años de experiencia. Identidades: Territorio, Cultura y Patrimonio, n. ${ }^{\circ}$ 2, Io. Recuperado en https://upcommons.upc.edu/bitstream/handle/2099/I0716/ID2_Saba-

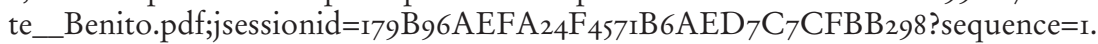

VAldés del Toro, R. (1987) Sobre Asturias y la cultura asturiana. En J. Rodríguez Muñoz (dir.) Enciclopedia de Temática asturiana, t. viII. Etnografía y folklore I (pp. 313-328). Gijón: Silverio Cañada, editor. 